\title{
ESTALLIDO SOCIAL Y VIOLACIONES A LOS DERECHOS HUMANOS EN CHILE*
}

\section{SOCIAL OUTBREAK AND HUMAN RIGHTS VIOLATIONS IN CHILE}

\author{
Johanna Guala Maldonado ${ }^{1}$ \\ jguala@indh.cl \\ Instituto Nacional de Derechos Humanos \\ Puerto Montt, Chile \\ DOI: HTTPS://DOI.ORG/10.32735/S2735-61752020000117149
}

\section{RESUMEN}

El año 2019 trajo consigo un sinnúmero de manifestaciones sociales en América Latina, las cuales, en el caso de Chile, se agudizaron a partir del 18 de octubre de 2019 en todo el territorio nacional. Mas allá de las causas de este fenómeno que han sido materia de múltiples análisis y discusiones, los hechos de violencia policial y la gran cantidad de violaciones a los derechos humanos, han puesto en cuestionamiento las obligaciones asumidas por el Estado en lo relativo a su respeto, garantía y protección de acuerdo al marco Internacional de derechos humanos tal y como es señalado en cuatro Informes de Organismos Internacionales y del INDH. Reflexionar en torno a esta discusión resulta imperativo y necesario para contribuir a una sociedad que cuente con un Estado más justo, respetuoso, que repare o restituya el daño causado y garantice la No repetición de actos que violen los Derechos Humanos.

Palabras claves: estallido social; violencia policial; violación de derechos humanos; organismos internacionales; INDH.

\section{ABSTRACT}

The year 2019 brought with it countless social demonstrations in Latin America, which, in the case of Chile, worsened from 18 October 2019 throughout the national territory. Beyond the causes of this phenomenon, which have been the subject of multiple analyses and discussions, the acts of police violence and the large number of human rights violations have called into question the obligations assumed by the State with regard to their respect, guarantee and protection in accordance with the international human rights framework, as indicated in four reports by international organisations and the INDH. It is imperative and necessary to reflect on this discussion in order to contribute to a society with a fairer and more respectful State, which makes reparation or restitution for the damage caused and guarantees the non-repetition of acts that violate human rights.

Key words: Social Outbreak; police violence; human rights violations; international organisations; INDH.

\footnotetext{
* Artículo recibido el 19 de noviembre de 2019; aceptado el 9 de marzo de 2020.

${ }^{1}$ Socióloga, Magíster en Trabajo Social y Políticas Sociales de la Universidad de Concepción, Diplomada en Introducción al Derecho Internacional de los Derechos Humanos de la Universidad de Chile.
} 


\section{Introducción}

El año 2019, fue un año de grandes agitaciones en varios países de América Latina: diversos medios dan cuenta por ejemplo, la situación de Haití en torno al reclamo de la ciudadanía por hechos de corrupción y por el deterioro de la situación Económica, solicitando la renuncia de su presidente Jovenel Moïse, calificada por BBC News (2019) como "una de las peores revueltas que ha vivido la convulsa Nación caribeña en los últimos tiempos"; Ecuador por su parte, vivencia una ola de movilizaciones a nivel nacional realizadas tras el anuncio de ciertas medidas económicas parte del Gobierno de Lenin Moreno a propósito de la finalización de los subsidios al combustible, además de una serie de reformas para estimular la economía del país, tal y como refiere el sitio GK (2019); en Puerto Rico las protestan inician para inducir la renuncia del gobernador Ricardo Rosello, máxima autoridad en ese Estado, por hechos de corrupción y la filtración de conversaciones entre este y Telegram, según reporta New York Times, (2019); en Bolivia, de una lado, para denunciar un supuesto fraude electoral ante la reelección presidencial de Evo Morales y de otro, para intentar restituir el orden constitucional ante su destitución, al respecto el sitio Portafolio (2019) menciona "Evo Morales, se encontraba este sábado en la cuerda floja acosado por colectivos civiles que protestan en las calles exigiendo su renuncia y por un motín policial que, según él, es un golpe de Estado "en marcha"'; en Colombia fue el descontento de gran parte de la población colombiana frente a las políticas económicas, sociales y ambientales del gobierno del presidente Ivan Duque, así como el manejo que se le habría dado a los acuerdos de paz con las FARC-EP y el homicidio de líderes sociales (campesinos, indígenas y reinsertados exguerrilleros), así como diversos casos de corrupción dentro del gobierno colombiano, según consignan fuentes tales como El Comercio (2019). Chile, por su parte, con una frecuencia semanal que duró meses, la revuelta social precipitó una crisis política, develó problemáticas estructurales que anteriormente carecían de atención o apoyo, y llevó a la sociedad entera a considerar la necesidad de hacer reformas profundas a la Constitución Política Nacional (Montes, 2020).

Pero, ¿Qué es, en definitiva, lo que mueve a un grupo importante y significativo de la población a movilizarse a través de la protesta social? Si bien este texto no podría arrogarse una respuesta concluyente, los cambios económicos y sociales producto de gobiernos con una tendencia conservadora o derechista, o bien políticas públicas que han causado impactos negativos en la población, han generado consecuencias en grupos que se han visto empobrecidos y para quienes los derechos económicos, sociales, culturales y ambientales se vuelven mezquinos, transformándose en prestaciones que agudizan las diferencias, perpetúan zonas de sacrificio o instalan la idea de que no somos todos iguales en dignidad y en derechos, tal y como lo señala la Declaración Universal de los Derechos humanos.

\section{El Contexto del estallido social}

Los movimientos sociales del año 2019, poseen en común las demandas contra los ajustes fiscales, la articulación de sectores populares, el resurgimiento de movimientos indígenas populares urbanos que enarbolan banderas indígenas y que expresan su descontento frente a la corrupción, frente al modelo económico extractivista y la presencia policiaca y militar represiva. Estos movimientos avanzan para reconstruir derechos básicos que no son respetados y garantizados por los Estados y los gobiernos de turno.

Chile, con un gobierno de derecha, no ha sido la excepción, distintos movimientos sectoriales (mapuches, estudiantiles, feministas), han logrado convocar una rebelión popular, una contracultura heterogénea y emancipadora, donde la acción colectiva toma protagonismo, donde el discurso descolonizador, la autogestión y la solidaridad permean el discurso y 
confrontan a un Estado autoritario, violento, represivo y con liderazgos políticos cada vez más desconectados de la realidad social de la población.

La población se ha organizado sin liderazgos aparentes, o claramente definidos e identificables, contra la existencia de un Estado alienado en la burbuja política partidista, alejado de la realidad nacional, para las mayorías, bajo el modelo socioeconómico excluyente, racista, extractivista y plutocrático, con una sociedad que vive las consecuencias de una carta fundamental dictatorial, que permite la acumulación de capital y el desarrollo económico a ciertos grupos privilegiados de la población. La protesta social y sus actuales manifestaciones se articulan a través de la participación directa, la afinidad en las demandas, la horizontalidad y la autoorganización.

Cabe destacar aquí, que el Derecho Internacional de los derechos humanos, protege el derecho a reunión pacífica. El Pacto Internacional de derechos Civiles y Políticos establece:

Se reconoce el derecho de reunión pacífica. El ejercicio de tal derecho sólo podrá estar sujeto a las restricciones previstas por la ley que sean necesarias en una sociedad democrática, en interés de la seguridad nacional, de la seguridad pública o del orden público, o para proteger la salud o la moral públicas o los derechos y libertades de los demás (ACNUDH, 1966, Art. 21).

Es decir, este instrumento permite a las personas expresarse colectivamente y participar en la configuración de sus sociedades lo cual, junto con otros derechos relacionados con la libertad política, constituye la base de un sistema de gobierno participativo basado en la democracia, los derechos humanos, el estado de derecho y el pluralismo. Cuando se usan para expresar quejas, las asambleas pacíficas pueden crear oportunidades para una solución inclusiva y pacífica de las diferencias y es deber de las autoridades del Estado, incluidos los funcionarios encargados de hacer cumplir la ley, facilitar y resguardar las manifestaciones. El uso de la fuerza debe realizarse con estricto apego a los requisitos que establecen las normas internacionales, como son Legalidad, es decir dirigido a un objetivo legal y empleando métodos legales, Necesidad, solo como último recurso de un Agente estatal para el cumplimiento de un deber y la Proporcionalidad, que refiere a la existencia de equilibrio entre la gravedad de la amenaza y la cantidad de Fuerza empleada.

Los funcionarios encargados de hacer cumplir la ley no utilizarán armas de fuego contra personas, excepto en defensa propia o en defensa de terceros contra la amenaza inminente de muerte o lesiones graves, para evitar la perpetración de un delito particularmente grave que implique una amenaza grave para la vida, para arrestar a una persona presentando tal peligro y resistiendo su autoridad, o para evitar su escape, y solo cuando los medios menos extremos son insuficientes para lograr estos objetivos. En cualquier caso, el uso intencional letal de armas de fuego 
solo se puede hacer cuando sea estrictamente inevitable para proteger la vida.

(ACNUDH, 2009, Art. 9).

A partir del 18 de octubre de 2019, la revuelta que inician los estudiantes secundarios días antes a propósito del alza de los pasajes y bajo la consigna "No son 30 pesos, son 30 años", da cuenta de un movimiento que va cada vez tomando más fuerza, buscando ocupar y apropiarse del espacio público urbano. Las redes sociales se transforman en un medio para comunicar, convocar e informar los hechos que se van suscitando y documentar a través de imágenes y denuncias, las graves violaciones a los derechos humanos ocurridas.

Así, la calle, la plaza pública y el barrio, logran protagonismo y son visibilizados como espacios de encuentro, de reivindicación a las demandas sociales, que cuestionan el modelo neoliberal, en donde se expresa la desconfianza respecto a la forma tradicional de hacer política, a las actuales y tradicionales formas de Organización, desafiando el orden social y político dominante e incluso a las históricas formas de organización sindical y movimientos sociales imperantes.

El contexto previo al Estallido social en Chile o las razones que llevaron al levantamiento ciudadano, ha sido analizado por diversos autores y forma parte ineludible de los informes emitidos por diversos organismos internacionales. Entre las razones, Akram (2020) plantea la reflexión inicial de porque si Chile proyectaba bienestar y mejoras significativas en su calidad de vida, había tanto descontento que genero una explosión social que vuelca a las calles a más de 4 millones de personas?, es así como a través de una revisión de cifras económicas y sociales analiza el actual modelo económico, constatando la desigualdad traducida en bajos salarios o sueldos estancados, endeudamiento, pensiones de miseria, falta de diversificación de la economía, falta de avances tecnológicos y un crecimiento mediocre. Plantea además las deficiencias del Estado subsidiario, que no regula y una clase política desgastada, tecnócrata que no gobierna con el movimiento social y que ha dado a luz a un nuevo actor social mundial, los rezagados de la sociedad cuya precariedad económica y social, explicarían la rabia que ha acompañado el estallido y que apelan a cambios políticos y económicos que se lograrían con el cambio constitucional que incorpore los derechos sociales para todos.

El estallido social, trajo consigo las más graves violaciones a los derechos humanos vistas en Chile, desde el retorno a la democracia, "El concepto de "violación a los derechos Humanos", se refiere a grandes rasgos, a cualquier acción u omisión que prive del goce de derechos garantizados, nacional o internacionalmente, a una persona o grupo de personas." (INDH, 2019). Dada esta situación el sistema de protección internacional de derechos humanos, enciende las alarmas y genera mecanismos de supervisión y constatación, luego de masivas denuncias de la ciudadanía a través de distintos medios, con el objetivo de indicar su veracidad, constatar las responsabilidades, así como hacer recomendaciones al Estado de Chile. Nuestro país, como muchos otros, ha adscrito de manera voluntaria, tratados y convenciones que establecen obligaciones a los Estados en cuanto al respeto, protección y garantía de los derechos de las personas, como garante y obligado al cumplimiento de estas.

Un Estado compromete directamente su responsabilidad internacional cuando sus agentes, o particulares con su aquiescencia o tolerancia, violan los derechos humanos de las personas que se encuentren bajo su jurisdicción. Así, es directamente responsable cuando un policía tortura o un funcionario público 
discrimina a una persona por su orientación sexual; y también lo es cuando un grupo de desconocidos, con tolerancia o complicidad de agentes del Estado, mata una persona. A su vez, se compromete indirectamente cuando, frente a una violación de derechos humanos, no cumple con el deber de prevenir, investigar y sancionar. Así, el Estado es responsable, por ejemplo, si no investiga y sanciona el asesinato de una persona, sin perjuicio de quién sea el autor del hecho. (INDH, 2010, p. 34).

\section{La mirada internacional y nacional, conclusiones y recomendaciones}

Cuatro son los informes internacionales que dan cuenta de lo ocurrido en nuestro país. Trataremos de resumir las principales observaciones o conclusiones, así como las recomendaciones que han puesto a Chile como un país, donde sus fuerzas policiales, principalmente carabineros, han violado de manera generalizada los derechos humanos de las personas en contexto de manifestación social. Todos ellos centran su análisis en los hechos ocurridos a partir del 18 de octubre de 2019 hasta Noviembre del mismo año.

En el ámbito internacional privado, Amnistía Internacional (Al, 2019), a través de su misión en Chile, concluye que:

$$
\begin{aligned}
& \text { Las fuerzas de seguridad bajo el mando del presidente Sebastián Piñera - } \\
& \text { principalmente el Ejército y Carabineros- están cometiendo ataques generalizados, } \\
& \text { usando la fuerza de manera innecesaria y excesiva con la intención de dañar y } \\
& \text { castigar a la población que se manifiesta. }
\end{aligned}
$$

El informe se estructura en un apartado que da cuenta de crímenes de derecho internacional, graves violaciones de derechos humanos, intencionalidad y generalidad (uso letal de la fuerza, tortura y malos tratos, lesiones graves y armas potencialmente letales) y limitación de trabajo de personas defensoras de derechos humanos. Entre las principales recomendaciones, el informe plantea el Cese de la represión dando máximas restricciones al uso de la fuerza, investigar las violaciones a los derechos humanos y la responsabilidad de mando, satisfacer demandas sociales y reformar a Carabineros (IA, 2019, p. 6)

Por otro lado, la Organización Human Rights Watch (HRW) informa de graves violaciones de Derechos humanos ocurridas en Chile a partir del 18 de Octubre de 2019, indicando que:

...miembros de la policía nacional de Chile (Carabineros) cometieron graves violaciones de derechos humanos, que incluyen uso excesivo de la fuerza en las calles y abusos en detención, luego de masivas protestas que comenzaron el 18 de octubre de 2019 y continuaron durante varias semanas. (HRW, 2019). 
Este informe da cuenta de uso indiscriminado e indebido de armas de fuego, otras lesiones causadas por Carabineros, problemas con las detenciones, maltratos, abusos sexuales y torturas durante en las detenciones e insuficiente rendición de cuentas por parte de Carabineros, además, trata las condiciones en que Carabineros realiza su labor y cierra con un apartado sobre uso de la fuerza. HRW, en definitiva, centra la responsabilidad de los abusos en el alto mando de carabineros, sin referirse al papel que cumplen las autoridades civiles que controlan el actuar de la policía. Sus recomendaciones se centran en las reformas a Carabineros y el cómo desempeñan su trabajo y las necesidades de investigación de los abusos. (HRW, 2019).

Los otros dos informes corresponden a instancias intergubernamentales de carácter internacional, una misión liderada por de la Oficina del alto Comisionado para los Derechos Humanos de Naciones Unidas (ONU) y otra por la supervisión de la Comisión Iteramericana de Derechos Humanos (OEA).

El secretario ejecutivo de la Comisión Interamericana de Derechos Humanos (CIDH), Paulo Abrao, lideró este informe que parte reconociendo una sólida institucionalidad democrática y de Derechos Humanos relevando el importante rol del Instituto Nacional de Derechos Humanos, Defensoría penal publica, Defensoría de la Niñez, la Contraloría General de la Republica y el Consejo para la transparencia. Coincidentemente con los anteriores informes reconoce:

Un alto número de violaciones a los derechos humanos denunciados en contexto de protesta social e insta a las autoridades de Chile a investigar con debida diligencia las denuncias de violaciones a los derechos humanos, a identificar y sancionar a los responsables e informar los resultados debidamente a la ciudadanía; condena el uso excesivo de la fuerza, y los graves desmanes en el curso de algunas manifestaciones.

Si bien pone énfasis en las acciones violentas durante las manifestaciones que dieron lugar a saqueos, perjuicios al sector privado y afectación a funcionarios de seguridad del Estado, deja constancia de la violación al derecho a la vida; del uso desproporcionado de la fuerza en el contexto de manifestaciones, incluidas lesiones a personal que realizaba labores de auxilio y asistencia médica; constata un elevado número de personas que han sufrido traumas oculares como consecuencias del impacto de perdigones o bombas lacrimógenas usados por Carabineros; releva una elevada cifra de detenciones desde el inicio de las protestas sociales y que estas violaciones "apuntarían hacia la existencia de conductas repetitivas de violencia en contra de manifestantes en el contexto de las recientes protestas sociales" (CIDH,2020), consagra casos de torturas y tratos crueles, inhumanos y degradantes en contexto de las detenciones, donde se denuncian:

simulacros de ejecuciones, grave maltrato físico y verbal, golpizas, hacinamiento en lugares sin ventilación y vejaciones injustas a niños, niñas y adolescentes, incluso de 
carácter sexual como violaciones, desnudamientos forzados, sentadillas, amenazas de violación y otras formas de maltrato sexual. (CIDH, 2020).

En cuanto a las recomendaciones la CIDH destaca el "cese inmediato del uso desproporcionado de la fuerza por parte de las fuerzas de seguridad del Estado", la reforma institucional de Carabineros, el fortalecimiento de las instituciones autónomas de derechos humanos y formula un llamado al diálogo para abordar las "demandas legítimas de la población"(CIDH, 2020). No obstante, aquello, la $\mathrm{CIDH}$ no es clara en condenar específicamente al Gobierno de su responsabilidad, poniendo énfasis en la obligación de investigar y sancionar, que tiene el Estado.

El cuarto informe corresponde a La Oficina del alto Comisionado para los Derechos humanos $(\mathrm{OACDH})$, pareciera ser el más completo y lapidario para el Estado de Chile. Se refiere al contexto que origina el estallido social, relacionándolo a una multiplicidad de causas, incluyendo la desigualdad social y económica, al respecto plantea que "a pesar de tener uno de los ingresos per cápita más altos de América Latina, Chile se encuentra entre los países de la región con altos niveles de desigualdad y con una riqueza altamente concentrada según CEPAL"(ONU, 2020, pag.4) y principalmente a aquellas causas vinculadas a la violación de los derechos económicos, sociales y culturales (DESC), así como las ya denunciadas formas de discriminación por los organismos de $\mathrm{DDHH}$ de la ONU principalmente a mujeres, pueblos indígenas y población LGBTI.

Al igual que en los otros informes presentados, las conclusiones plantean que:

Hay razones fundadas para sostener que, a partir del 18 de octubre, se han producido un elevado número de violaciones graves a los derechos humanos. Estas violaciones incluyen el uso excesivo o innecesario de la fuerza que resultaron en la privación arbitraria de la vida y en lesiones, la tortura y malos tratos, la violencia sexual y las detenciones arbitrarias. Estas violaciones se cometieron en todo el país, pero su gran mayoría ocurrió en la Región Metropolitana y en contextos urbanos. (ONU, 2020, p. 31).

Asimismo, el informe da cuenta de ejecuciones extrajudiciales y también que adolescentes y jóvenes constituirían la mayoría de las presuntas víctimas de violaciones a los derechos humanos, así como mujeres, niñas y población LGBTI, habrían sido principalmente víctimas de violencia sexual (desnudez forzada).

En cuanto a las lesiones oculares plantea el:

...número alarmantemente alto de personas con lesiones en los ojos o la cara da cuenta de esta grave violación -y manifiesta preocupación por- la utilización de perdigones que contienen plomo...que hubo una omisión por parte de los 
responsables al no adoptarse medidas eficaces, expeditas y oportunas para minimizar el riesgo para las personas (ONU, 2020, p. 30).

Situación que colocaría la responsabilidad en las autoridades políticas a cargo del accionar policial (Ministerio del Interior y el propio Presidente Sebastián Piñera). Además, se denuncia que un gran número de las personas arrestadas y detenidas fueron víctimas de maltratos y Tortura señalando que muchos de estos casos ocurrieron en lugares sin cámaras de vigilancia y con los perpetradores no debidamente identificados. Pone énfasis en el rol de Carabineros como la institución con un mayor compromiso en las violaciones de $\mathrm{DDHH}$.

Acerca de las recomendaciones, un grupo de ellas está destinado a medidas correctivas de la actuación del Estado en el contexto de las manifestaciones, las que están básicamente dirigidas al cumplimiento de la normativa interna e internacional.

En cuanto a Carabineros, se recomienda adoptar medidas y reformas estructurales para asegurar la supervisión civil y el monitoreo independiente de sus actividades, fortaleciendo la transparencia, el acceso a la información y la rendición de cuentas como principios rectores, reformas al sistema de registros de detención; capacitación de vanguardia; regulaciones para protección de personas y grupos discriminados; utilización de identificación adecuada en actividades de seguridad pública. (ONU, 2020, p. 30).

Propone medidas para evitar la impunidad en los casos de tortura incorporando el uso de los protocolos internacionales (Estambul y Minnesota) para las investigaciones; y, exámenes médicos después del arresto y mantención de registros médicos, fortaleciendo también la Institucionalidad a cargo de estas diligencias (SML, Ministerio público).También que los Organismos Nacionales de DDHH como INDH, mecanismo de Prevención contra la Tortura y Defensoría de la niñez cuenten con el presupuesto necesario para el cumplimiento de su mandato.

La rendición de cuentas e investigación de violación de $\mathrm{DDHH}$, es bien interesante puesto que se pide el reconocimiento de las violaciones de derechos por parte de Carabineros y el aceleramiento de las investigaciones garantizando el acceso a la justicia de las víctimas, proponiendo fiscales y/o jueces especializados en $\mathrm{DDHH}$ y una reparación integral de acuerdo a las vulneraciones sufridas. En cuanto a las medidas de protección, se recomienda que defensores de $\mathrm{DDHH}$, periodistas y personas que brindan asistencia de salud puedan realizar sus labores. Además, recomienda que el derecho penal no se utilice para restringir a quienes ejercen su derecho a reunirse pacífica y libremente y las autoridades deben abstenerse de dichos que puedan "criminalizar la protesta" (ONU, 2020, p. 34).

Por último, OACDH propone, la creación de un mecanismo para "recopilar, sistematizar y hacer pública la información" de las violaciones de DDHH. También se recomienda un mecanismo participativo (Sociedad civil, Academia, Gobierno y sector Privado), para "identificar las causas estructurales de las protestas" y, en particular, las relacionadas con DESC y discriminación.

En el plano Nacional, por su parte, el Instituto Nacional de Derechos Humanos, en su Informe anual 2019 concluye que:

Los datos analizados -especialmente en lo que respecta a los derechos a la vida, la integridad física, psíquica y moral; la prohibición de la tortura y otros tratos o penas 
crueles, inhumanos o degradantes y, libertad personal y seguridad individual- dan cuenta que la mayor proporción de las violaciones a los derechos humanos ocurrieron durante la vigencia del estado de emergencia, con las Fuerzas Armadas y Carabineros a cargo del orden público, siendo esta última la institución con la mayor cantidad de violaciones a los derechos humanos. (INDH, 2019, pp. 81 y 82).

Señala además que el Estado de Chile deberá reforzar los pilares de la justicia transicional, estos son Verdad, Justicia, Reparación y Garantías de No repetición. Se recomienda al poder ejecutivo:

disponer de todos los esfuerzos para que la actuación de las Fuerzas de Orden y Seguridad Pública, en especial el uso de la fuerza, se realice, efectivamente y desde ya, con estricto apego al respeto de los derechos humanos, de manera que responda a los principios de legalidad, necesidad, proporcionalidad y responsabilidad. (INDH, 2019, p. 84).

También propone la reforma al marco normativo de las fuerzas de orden y seguridad, así como asegurar la justicia y la No impunidad en materia de investigaciones de violaciones a los derechos humanos y también se refiere a la imperativa necesidad de que el estado establezca medidas concretas en el ámbito de la reparación a las víctimas, que sean "pertinentes y adecuadas al daño provocado a las víctimas, que contemple el acceso prioritario y especializado a prestaciones de salud física y mental, rehabilitación e indemnizaciones" (INDH, 2019, pag.86). Dicho informe, termina recomendando la necesidad de fortalecer la valoración de los derechos humanos y la democracia, así como el fortalecimiento de los derechos económicos, sociales, culturales y ambientales (DESCA).

Posteriormente en su Informe de Seguimiento, el INDH a más de un año de la emisión de su informe anual, plantea, en palabras de su Director que "al día de hoy estamos más cerca de la impunidad que de la verdad y la justicia"(Radio U.Chile, 2021) respecto a las violaciones ocurridas desde el 18 de Octubre de 2019, es decir, en definitiva el Estado no ha cumplido, o solo de manera parcial, con las recomendaciones para superar la crisis más grave en materia de derechos humanos desde el retorno a la democracia, que posterior al periodo analizado por los cuatro informes antes descritos, las violaciones de derechos humanos continúan, se siguen produciendo daños gravísimos por uso ilegítimo de escopetas de perdigones, ha aumentado el uso de agentes químicos con graves efectos en la población, los órganos judiciales han fallado en el deber de proteger los derechos humanos, en la búsqueda de verdad y en sancionar a los culpables de estas violaciones y tampoco ha habido un compromiso real en cuanto a financiamiento de programas o políticas públicas en la Reparación a las víctimas que han sufrido trauma ocular, las que han necesitado rehabilitación física o psicológica ya que no cuentan con apoyos económicos, sociales y jurídicos; la poca oferta existente de programas, han sido diseñados sin la participación de las víctimas y han estado concentrados en Santiago, sin considerar que el estallido social, fue un fenómeno de carácter nacional. 
Con respecto a los casos de violencia sexual, el INDH señala que no existe un programa adecuado y especializado que aborde aspectos psicológicos, económicos, sociales y jurídicos, dado que el Ministerio de la Mujer y la Equidad de Género en esta materia (violencia sexual) no contempla la violencia de agentes del Estado, esto es, su labor no contempla un enfoque de derechos humanos y tampoco está orientado a grupos de especial protección como son las personas LGTBI.

Según los últimos reportes del año 2021, el INDH ha presentado "2.520 querellas por violaciones a los derechos humanos en contexto del estallido social, que consideran 3.203 víctimas" (INDH, 2021), solo una causa de este periodo, está actualmente con sentencia condenatoria. Por su parte el Ministerio público, con datos abarcados desde el 18 de octubre 2019 hasta el 18 de marzo 2020, la Unidad Especializada en Derechos Humanos, informa que fueron 8.827 los casos ingresados al sistema durante el periodo, de estas 4.681 (Fiscalía, 2020), se encuentran vigentes, es decir el $47 \%$ estarían cerradas sin formalizaciones o sin avances. Este panorama, reafirma lo desesperanzador que resulta el proceso de investigación de estas causas, a más de un año del estallido social, la población no confía en las Instituciones generando un sentimiento de impunidad e injusticia.

\section{Conclusiones}

Lo expuesto en este ensayo, luego de la revisión de los hechos acontecidos a partir del Estallido o sublevación de Octubre de 2019, así como las recomendaciones de los organismos nacionales e internacionales, es menester reflexionar, en el actual y esperanzador proceso constituyente respecto a los desafíos en materia de derechos humanos que tanto como sociedad y Estado tenemos por delante.

En primer lugar, si bien los procesos de exigibilidad al Estado a través del cumplimiento de la normativa vigente y la persecución penal, es un imperativo en el sentimiento de injusticia de quienes han sido víctimas, el panorama actual, no contribuye a minimizar sus efectos, transformándose en una deuda pendiente. Pero si bien esta dimensión jurídica es muy importante para limitar el poder del Estado, establecer jurisprudencia y garantizar la no repetición de estos actos, los derechos humanos son más que la norma impresa y sería un error circunscribir su resolución, a la mera interposición de un recurso judicial.

Las ciencias humanas y sociales, la cultura, las artes y la sociedad en general, también tienen un papel protagónico para disminuir la brecha de conocimiento y reconocimiento del otro/a como sujeto de derechos, para contribuir a una cultura respetuosa de los derechos humanos y dejar atrás las miradas odiosas y discriminatorias basadas en diferencias de sexo, origen social, políticas o cualquier otra índole, que tanto daño hacen a la convivencia diaria, en un estado democrático.

Si bien existe una deuda en materia de Educación en derechos humanos en la población en general, los avances en esta materia, han estado ligados principalmente con experiencias históricas de violaciones sistémicas vividas durante la dictadura cívico-militar. La encuesta nacional de DDHH del año 2020 plantea que el 16\% de los encuestados manifiesta no saber nada de este tema, mientras que el $43 \%$ plantea que en Chile existe poco respeto a estos y que hoy existe menos respeto que hace 5 años atrás. (INDH, 2021, p. 34). En cuanto a la valoración a la democracia, si bien los niños, niñas y adolescentes manifiestan que es absolutamente importante vivir en un país democrático, el $19 \%$ de los adultos manifiesta que Chile es una sociedad para nada Democrática. 
Para el goce, defensa y protección de los derechos humanos, la Educación (formal o no formal), cumple un rol fundamental como facilitador, es por esto que, en materia de promoción y educación en derechos Humanos, se evidencia una falta de conocimiento y capacitación de funcionarios/as públicos/as. De acuerdo al Estudio Diagnostico de Capacitación y Formación en Derechos Humanos de servicios públicos de la Subsecretaría de Derechos Humanos el año 2018, la cobertura de capacitaciones en esta materia para los años 2016-2017 resulta marginal en relación a todas las capacitaciones de los servicios. Según datos del Servicio Civil en el mismo periodo se consignaron 6.266 actividades, de las cuales sólo 488 correspondieron a Derechos Humanos o temáticas asociadas, es decir solo un 7,7\% a nivel nacional. De este modo, reforzar una cultura respetuosa de derechos humanos en todos los espacios resulta un importante desafío en el actual contexto de discusión constitucional.

El refuerzo de la Institucionalidad de Derechos Humanos, también podría fortalecer el sistema de protección y los mecanismos de reclamación. Contar con un INDH con rango constitucional que fortalezca su autonomía y genere mayores facultades que las que establece su ley 20.405, además de impulsar otros mecanismos o estrategias de acuerdo a la experiencia internacional, como el Ombudsman o la defensoría del Pueblo, con la participación de distintos actores, permitiría evitar la repetición de los hechos acontecidos recientemente y de los cuales esperamos no seguir normalizando.

En materia reparatoria, resulta imperativo restituir la confianza de los ciudadanos en el Estado y sus instituciones. La creciente desconfianza ha tenido como efecto el hecho de que las personas, principalmente niños, niñas y adolescentes de sectores populares, además de quienes han tenido experiencias traumáticas de violencia estatal, no denuncian los hechos de los cuales han sido víctimas, de modo que el Estado, debe generar acciones que fortalezcan la confianza y credibilidad. Fortalecer programas sicosociales en la estructura del Estado o fuera de ella, que den respuesta efectiva a las necesidades frente a experiencias traumáticas, que puedan responder a los desafíos que ha impuesto la experiencia y trate de remediar, los abusos de los agentes del estado. Esta restitución entendida como un intento de remediar el daño causado y la vuelta al estado inicial, previo a la vulneración, debe contar con un tratamiendo adecuado, pertinente, con perspectiva de género e intercultural que ponga en el centro la dignidad de la persona y no la revictimice.

La reparación, no es tan solo un mecanismo de indemnización, la jurisprudencia de la Corte IDH da cuenta que la reparación integral implica adoptar medidas relativas a la restitución, rehabilitación y satisfacción de las víctimas, así como adoptar garantías de no repetición y la obligación de investigar los hechos, determinar a sus responsables y, en su caso, sancionar. (Calderón, 2013).

En lo judicial, debiera existir una estrategia de priorización, que logre identificar patrones macro criminales:

El concepto de patrones constituye la base de ciertas metodologías de investigación de hechos de graves violaciones de derechos humanos. Dichas metodologías han sido utilizadas en diversas experiencias a nivel nacional e internacional, dirigidas a 
superar las investigaciones fragmentadas que tratan casos similares de forma aislada, desarrollando en su lugar estrategias globales de investigación. La identificación de patrones contribuye a la caracterización de prácticas y modus operandi, con el objetivo de guiar la construcción de hipótesis y el trabajo de recolección de la prueba. En la misma línea, la atención a los patrones resulta clave para el diseño de las estrategias de priorización. Por otro lado, la identificación de patrones contribuye a caracterizar el contexto en que ocurren las violaciones de derechos humanos, permitiendo construir estrategias globales para el abordaje de los casos. En consecuencia, al comprender que una serie de hechos se insertan en un mismo contexto, será más factible la homologación de criterios de actuación respecto al uso adecuado de categorías penales; la no aplicación de términos facultativos y salidas alternas; el diseño de estrategias transversales para la recolección de prueba. (CEJA, 2020.pag 138).

La idea seria establecer metodologías de investigación especializada para este tipo de delitos, tomado en consideración el contexto de estos, es decir el contexto de manifestación social, recoger la experiencia internacional y una Fiscalía especializada en Derechos Humanos, con profesionales de dedicación exclusiva, que cuente con recursos materiales, tecnológicos e infraestructura adecuada para desarrollar su trabajo.

Es de esperar que el nuevo proceso constitucional ya en curso, se transforme en un camino que pueda dar respuesta a estos y otros desafíos y que constituya, una nueva carta fundamental en donde los derechos humanos sean el hilo conductor de la acción del Estado. 


\section{Referencias}

ACNUDH. (16 de diciembre, 1966). Pacto Internacional de Derechos civiles y políticos. Recuperado de: https://www.ohchr.org/sp/professionalinterest/pages/ccpr.aspx

ACNUDH. (1990). Principios Básicos sobre el Empleo de la Fuerza y de Armas de Fuego por los Funcionarios Encargados de Hacer Cumplir la Ley.

Akram, H. (2020). El Estallido. ¿Por qué? ¿Hacia Dónde? Santiago de Chile: Editorial El Desconcierto.

Amnistía Internacional. (2019). Ojos Sobre Chile: Violencia policial y responsabilidad de mando durante el estallido social.

Amnistía Internacional. (21 de noviembre, 2019). Chile: Política deliberada para dañar a manifestantes apunta a responsabilidad de mando. Recuperado de: https://www.amnesty.org/es/latest/news/2019/11/chile-responsable-politica-deliberadapara-danar-manifestantes/

BBC News. (15 de febrero, 2019). Protestas en Haití: cómo las manifestaciones contra el gobierno acabaron en una violenta crisis en el país más pobre de Occidente. Recuperado de https://www.bbc.com/mundo/noticias-america-latina-47234523

Calderón, J. (2013). La Reparación Integral en la Jurisprudencia de la Corte Interamericana de Derechos Humanos: Estándares aplicables al nuevo paradigma mexicano. Instituto de Investigaciones Jurídicas UNAM. Recuperado de: https://www.corteidh.or.cr/tablas/r33008.pdf

CEJA. (2020). Evaluación del sistema de justicia de Chile ante las violaciones de derechos humanos ocurridas en el contexto de la protesta social. Santiago de Chile: Centro de Estudios de Justicia de las Américas.

CIDH. (2020). CIDH culmina visita in loco a Chile y presenta sus observaciones y recomendaciones preliminares. Comunicado de Prensa. Recuperado de: https://www.oas.org/es/cidh/prensa/comunicados/2020/018.asp

El Comercio. (13 de noviembre, 2019). Colombia: Convocan paro nacional contra gobierno de Iván Duque para el 21 de noviembre. Recuperado de: https://elcomercio.pe/mundo/latinoamerica/colombia-convocan-paro-nacional-contragobierno-de-ivan-duque-para-el-21-de-noviembre-noticia/

Fiscalía de Chile. (16 de octubre, 2020). A un año del 18-O: Fiscalía ha formalizado a más de 5 mil personas por delitos cometidos en el contexto del Estallido social. Recuperado de: http://www.fiscaliadechile.cl/Fiscalia/sala_prensa/noticias_det.do?noticiald=18771

GK. Transportistas paralizan el país por la eliminación del subsidio a los combustibles. (03 de octubre, 2019). Recuperado de: https://gk.city/2019/10/03/paro-nacional-en-ecuador/

Human Rights Whatch. (26 noviembre, 2019). Chile: llamado urgente a una reforma policial tras las protestas. Recuperado de: https://www.hrw.org/es/news/2019/11/26/chile-llamadourgente-una-reforma-policial-tras-las-protestas

INDH. (2010). Informe Anual: Situación de los Derechos Humanos en Chile.

INDH. (2019). Informe Anual: Sobre la situación de los Derechos humanos en Chile en el contexto de la crisis social, 17 de octubre-30 de noviembre de 2019. Recuperado en https://bibliotecadigital.indh.cl/bitstream/handle/123456789/1701//nforme\%20Final2019.pdf?sequence=1\&isAllowed=y\%20pag. $\% 2022$

INDH. (2021). INDH entrega balance a un año de crisis social. Recuperado de: https://www.indh.cl/indh-entrega-balance-a-un-ano-de-la-crisis-social/

INDH. (2021). Informe de resultados: Encuesta Nacional de Derechos Humanos 2020.

Micco, S. (02 de junio, 2021). Estamos más cerca de la impunidad que de la verdad y de la justicia. Recuperado de: https://radio.uchile.cl/2021/06/02/sergio-micco-estamos-mascerca-de-la-impunidad-que-de-la-verdad-y-la-justicia/ 
Montes, R. (18 de enero de 2020). Aumenta el rechazo al mundo político a los tres meses de la crisis

en

Chile. El

País.

Recuperado

de:

https://elpais.com/internacional/2020/01/18/america/1579370590_207046.html

ONU. (2020). Informe sobre la Misión a Chile, 30 de octubre - 22 de noviembre 2019.

Portafolio. (09 de noviembre, 2019). Evo Morales en la cuerda floja por rebelión nacional en Bolivia: A los motines adhirieron la noche del viernes unidades policiales de siete de los nueve departamentos del país. Recuperado de: https://www.portafolio.co/internacional/evo-en-la-cuerda-floja-por-rebelion-nacional535425

The New York Times. (22 de julio, 2019) ¿Por qué hay protestas en Puerto Rico? Recuperado de: https://www.nytimes.com/es/2019/07/22/espanol/america-latina/protestas-puertorico.html 